Jour. Japan. Assoc. Min. Pet. Econ. Geol., Vol.47, February, 1962

\title{
EPIGENETIC CONCRETIONARY STRUCTURE FROM YAMAGATA
}

(Recieved Dec. 20, 1961)

\author{
Kotora Hatai and Osamu Yamagata \\ Institute of Geology and Paleontology. Tohoku University \\ and Department of Geology, Yamagata University
}

Introduction AND ACKNOWLEdGements

Concretionary structures are common in the Miocene sediments of the oil-fields of northwestern Japan, but among them true concretions are not so abundant: Most of the concretionary structures are derived from some original layer to which they can be traced and therefore are pull-apart structures, rounded to different grades by which they resemble concretions. Among the concretions known from the oil-field region of northwestern Japan probably only the Gennoishi, a pseudomorph after gaylussite, have been described and illustrated, whereas the others have been only indicated in reports on the local geology.

The concretionary structure described in this article was found embedded in the gouge of a nearly 20 centimeters wide fault in which several other similar structures were also discovered. Owing to the mode of occurrence, material, orientation in the gouge and peculiar internal structure, it is thought to be worthy of description.

Here the writers wish to thank Dr. Kei-ichi Omori, Professor of Mineralogy, Institute of Economic Geology, Petrology and Mineralogy, Tohoku University, for his kind information on the internal structure of the concretion. Thanks are also due to $\mathrm{Mr}$. Kyoichi Masuda, former Director of the Electric Power Plant, Yamagata Prefecture Office, for his gift of the interesting specimen. The writers also thank Mr. Kimiji Kumagai of the Institute of Geology and Paleontology, Tohoku University, for taking the necessary photographs.

\section{MOde OF OCCURRENCE AND Locality}

The specimen described and illustrated in this article was 
found in a whitish gouge of $15^{-20} \mathrm{~cm}$ in thickness of the fault trending $\mathrm{N} 40^{\circ} \mathrm{E}$ and dipping $60-70^{\circ} \mathrm{E}$ at about one $\mathrm{Km}$ southwest of Magaribuchi, Asahi-machi, Nishi-Murayama-gun, Yamagata Prefecture (Fig. 1). The concretion specimen was found near the middle part of the gouge arranged with others more or less in a single row parallel with the fault plane and with the axis perpendicular with the fault plane and more or less parallel with the bedding plane. In this area there are developed and distributed hard marine sandy shales which correspond to the Onnagawa formation of the standard sequence in Akita Prefecture. The normal fault observed in the tunnel for irrigation purpose cuts the hard sandy shale deposits and the gouge is composed of finsly crushed whitish clay. No fossils of the formation were found in the gouge, but besides the concretion, angular fragments of crushed sandy shale occurred in subordinate amount. The present locality of the specimen is now covered with cement beciuce the tunnel was made for irrigation purpose.

\section{DESCRIPTION OF THE CONCRETION}

The present specimen is roughly barrel-shaped, measures about $5.5 \mathrm{~cm}$ in maximum lergth, nearly $4 \mathrm{~cm}$ in the depressed central

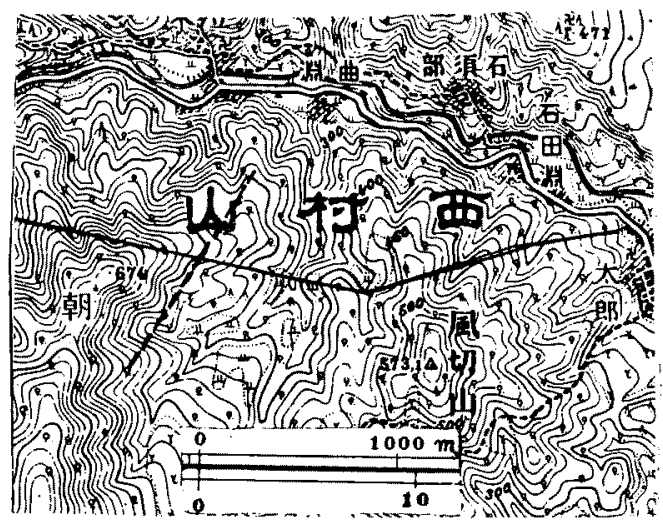

Fig. 1. Dashed line represents the fault, the straight line the tunnel, and the specimen is from the crosspoint of the two lines. 
part, and a little more than $6 \mathrm{~cm}$ in maximum diameter. The surface is very rough, being with numerous irregular shaped pits of varied sizes and depths though none of them are round-bottomed, and the color is dark grayish brown. The external sides of the barrelshaped concretion are almost straight and parallel with one another although a little convex outwards, but near their flattened parts the lateral sides are shaiply and roundly curved into the nearly flat but centrally depressed upper and lower surfaces. The depressed area on both upper and lower surfaces measure about $2.5 \mathrm{~cm}$ in diameter and are depressed nearly $7 \mathrm{~mm}$. The depressed areas are more or less flat-bottomed or saucer-shaped and with more or less well defined sides. The outer sides of the depressed areas are circumscribed by

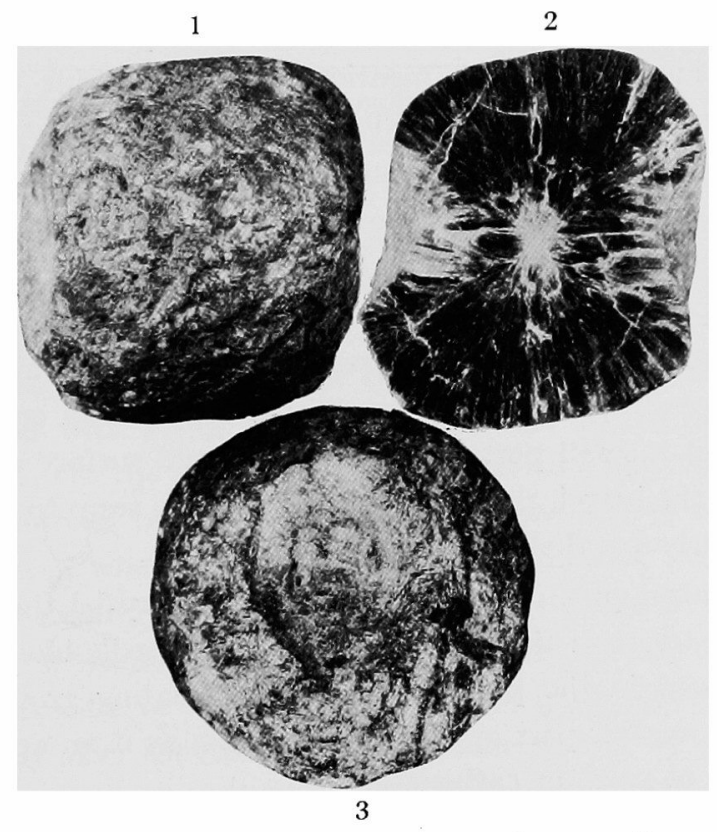

Fig. 2. Different views of epigenetic concretion.

1. External view in natural orientation, showing roughened surface and flattened extremeties.

2. Polished section showing growth of calcite crystals and blurred center.

3. View of flattened extremity showing depressed central portion demarked by a well defined rim. This depression was originally filled with gouge. 
vague yet more or less well defined ridges which delimit the more or less flat upper and lower surfaces of the barrel from the depressed areas.

The polished surface cut through nearly the central part of the specimen parallel with the length shows resin lustre mottled in the central part as if by a nucleus and near to the depressed areas as if by fractured crystals. The crystals below the depressed areas are arranged more or less perpendicular to the upper and lower flat surfaces, being shorter near the lateral sides and gradually becoming longer towards the central part or the nucleus. The lateral extremities of the crystals showing growth perpendicular to the upper and lower surfaces are defined externally by the rim or ridge bordering the outer sides of the depressed areas already mentioned. From the outer sides of the just mentioned ridge or rim towards the lateral sides of the barrel the crystals all show a radiating pattern, extending outwards from the nucleus-like central part. The perpendicular cystals above mentioned abut against the outermost radiating ones, forming there a distinct boundary. This boundary although appearing distinct and sharp due to the different trends in crystal growth of radial and perpendicular to the lateral and upperlower surfaces respectively, is actually graditional in certain parts. Especially in a small portion near the external surface close to the shoulder of the barrel, the perpendicular crystals seem to converge to become nearly parallel with the radiating ones.

The central part of the specimen which may be the nucleus is of lighter color than the other parts and the needle-like crystals so well developed in the perpendicular and radiating groups are not seen. This nuclear part appears more or less as if an accumulation of granules of calcium carbonate.

Observed under low magnification the crystals seem to be characterized as follows. In the central nuclear part the aggregates of small crystals of irregular form interlock, whereas at their outer peripheral parts they gradually grow into calcite crystals of needle form. The extremities of the crystals in the depressed area do not show good development and appear as if stunted, whereas at the 
lateral parts such features are not observed. This difference in growth of their extremities seems to be related with the growth of the concretion itself. The recrystallized calcites of the perpendicular and radial series already mentioned show also features of growth under stress; the latter show normal growth contrary to the abnormal growth of the former.

It may be added that the two series of crystals are formed within angles of about $52^{\circ}$ for the perpendicular ones and at about $128^{\circ}$ for the radial ones, in other words the former of stress and the latter of released stress. For this reason both sets are formed in fanshaped areas defined by planes of intersecting stress couple.

\section{INTERPRETATION OF THE CONCRETION}

Interpretation of the crystal aggregate described above is given in the following lines. The aggregates, gravels or concretions as they may be called, occur in a $15-25 \mathrm{~cm}$ thick fault-gouge between displaced hard sandy shale deposits of early Miocene age. The concretion-like structures are oriented with their depressed or flat surfaces facing the fault walls and the broadly rounded barrel walls perpendicular to the walls. For this reason the depressed areas are tightly filled with gogue as if the latter was forced partially into the former. On the other hand it may be said that the depressed areas are nothing but local regions of compression or resistance to crystal growth whereby stunting of them resulted. Conversely the external area of the lateral sides of the barrel owing to the released pressure or stress favored the growth of the crystals even though confining pressure or resistance of the fault gouge prevailed. It is thought that after accumulation of granular calcite by precipitation from ground water there was developed a nucleus, and by the continued supply of calcium carbonate the crystals of calcite were able to growth. However, by the resistance of the two rigid fault-walls, lateral growth of the crystals was hindered, but in the areas of less resistance growth of the calcite crystals continued.

The epigenetic growth of the present concretion can be explained in part, by the different growth of the calcite crystals of two sets, 
their oriented development, mode of occurrence and in there being no evidence of shear or fracture by the fault. Their internal structures are also important evidence. It is most probable that these concretions or crystal growths were not developed during diagensis of the shale deposits because of their peculiar shapes, orientation with the gouge of the normal fault, absence in observed outcrops of the hard sandy shale deposits, and internal structures. Also, if the concretion was developed before fault activity, their axis should be inclined in the direction of the down-throw side and not be more or less horizontal in position. If they were derived from an older sedimentary deposit and subsequently incorporated in the fault gouge, they should occur with random orientations and have smoother external surface because some erosion must have accompanied them.

Another possibility would be that shearing or fracturing of the concretions should be preserved if they had any relation with fault activity.

For the stated reasons it is interpreted that the present specimen is a concretion of calcite crystals which had developed at a time later than the fault activity and under confining differential pressure.

\section{REFERENCES}

Hanna, M. A., Barite concretions from the Yazoo clay, Eoene, of Louisiana. Sed. Petr., Jour., 6, 28-30, 1936.

Hiki, T., On the Gennoishi. Kyoto Imp. Univ., Coll. Eng., Mem., 1, no. 2, 55-58, pl. 1-2, 1921.

Revelle, R., and Emery, K.O., Barite concretions from the ocean floor. Geol. Soc. Amer., Bull., 62, 707-724, 1 text-fig., 5 tables, pl. 1-2, 1951. 